\title{
I want to quit education: A longitudinal study of stress and optimism as predictors of school dropout intention
}

\author{
Véronique Eicher", Christian Staerklé, Alain Clémence \\ Swiss National Centre of Competence in Research "LIVES”, University of Lausanne, Switzerland
}

Keywords:

Dropout intentions

Education

Stress

Optimism

Longitudinal

\begin{abstract}
A B S T R A C T
Prior research on school dropout has often focused on stable person- and institution-level variables. In this research, we investigate longitudinally perceived stress and optimism as predictors of dropout intentions over a period of four years, and distinguish between stable and temporary predictors of dropout intentions. Findings based on a nationally representative sample of $16-20$ year-olds in Switzerland $(N=4312)$ show that both average levels of stress and optimism as well as annually varying levels of stress and optimism affect dropout intentions. Additionally, results show that optimism buffers the negative impact of annually varying stress (i.e., years with more stress than usual), but not of stable levels of stress (i.e., stress over four years). The implications of the results are discussed according to a dynamic and preventive approach of school dropout.

(C) 2014 The Foundation for Professionals in Services for Adolescents. Published by Elsevier
\end{abstract} Ltd. All rights reserved.

\section{Introduction}

Students who drop out of school often face negative consequences such as unemployment and lower standards of living (Belfield \& Levin, 2007). It is therefore important to detect the social and psychological factors that first give rise to dropout intentions and eventually lead to actual dropout. In this study, we investigate dropout intentions longitudinally over a period of four years by focusing on both person-level predictors and predictors that may vary over time. In doing so, we want to better understand how temporary psychological factors influence dropout intentions over and above previously documented stable person characteristics and performance indicators.

\section{Predicting who drops out}

At the individual level, findings consistently show that poor academic and cognitive performance (Alexander, Entwisle, \& Horsey, 1997; Balfanz, Herzog, \& Mac Iver, 2007) as well as deviant behavior (e.g., school absenteeism, substance abuse; Archambault, Janosz, Fallu, \& Pagani, 2009; Battin-Pearson et al., 2000; Ellenbogen \& Chamberland, 1997) predict school dropout. Moreover, men and minority members (e.g., immigrants) are more likely to drop out (Finn, Gerber, \& Boyd-Zaharias, 2005; Laird, Kienzi, DeBell, \& Chapman, 2007; Rumberger, 1987), although this effect often disappears when controlling for academic performance, attitudes, and behaviors (Rumberger, 1995). The impact of relevant attitudes seems more inconsistent: While low educational expectations are associated with dropout (Driscoll, 1999), the association between self-perceptions

\footnotetext{
* Corresponding author.

E-mail address: veronique.eicher@unil.ch (V. Eicher).
} 
(e.g., self-esteem, locus of control) and dropout is inconsistent and weak (Alexander, Entwisle, \& Kabbani, 2001; Rumberger, 1995). Recent studies in Finland and the U.S. have, however, shown that cynicism as well as lack of perceived control and identification with school predict dropout, even when controlling for educational performance (Bask \& Salmela-Aro, 2013; Fall \& Roberts, 2012).

On the family level, low socio-economic status (SES) has been one of the most powerful predictors of dropout (Dunham \& Wilson, 2007; Entwisle, Alexander, \& Steffel Olson, 2004), along with family structure (e.g., parents living in different households, Perreira, Harris, \& Lee, 2006) and being a first-generation student (Ishitani, 2006). Additionally, student composition, resources, and classroom climate in schools have been shown to influence school engagement and dropout prevalence within a given educational context (Dotterer \& Lowe, 2011; Loeb \& Page, 2000; Rumberger, 1995). Research on the type of schooling (e.g., college-track vs. vocational training) is more ambiguous: Some studies show fewer dropouts in careertechnical courses while others show no effect (Bishop \& Mane, 2004; Pittman, 1991).

Several models of dropout have integrated these different risk factors to explain student dropout (e.g., Appleton, Christenson, \& Furlong, 2008; Bean \& Metzner, 1985; Spady, 1970; Tinto, 1975). Tinto (1975), for example, focused on academic and social integration as factors leading to institutional commitment, persistence and goal engagement. Bean and Metzner (1985) revised this model for nontraditional students (i.e., older, non-residential, and part-time), stressing the role of environmental (e.g., financial situation, family responsibilities) and psychological variables (e.g., stress, satisfaction) in predicting dropout.

Bean and Metzner (1985) also explicitly considered intention to drop out of education as "the strongest single predictor of dropout" (Bean \& Metzner, 1985, p. 527). This link between dropout intentions and actual dropout was subsequently confirmed by various studies (Davis, Ajzen, Saunders, \& Williams, 2002; Metzner \& Bean, 1987; Sandler, 2000; Thomas, 2000; Vallerand, Fortier, \& Guay, 1997). Research specifically investigating dropout intentions has furthermore confirmed the predictive impact of psychological variables such as goal engagement and intrinsic motivation (Braxton, Vesper, \& Hossler, 1995; Otis, Grouzet, \& Pelletier, 2005), institutional commitment (Braxton et al., 1995; Hausmann, Schofield, \& Woods, 2007; Zea, Reisen, Beil, \& Caplan, 1997), as well as social support (Hausmann et al., 2007; Thomas, 2000) that are all negatively associated with dropout intentions. Starting from the basic model of Bean and Metzner (1985), the present study examines the role of two neglected psychological variables-educational stress and optimism-as predictors of dropout intentions.

Stress, optimism, and coping

Neither stress nor optimism have received much attention in research on dropout intentions, although both may intervene in coping with the difficulties that push young people to leave school. In general, stress is defined as an imbalance between demands and resources (Lazarus, 1999). More specifically, we consider educational stress as the feeling of being overwhelmed by school demands. Investigating the role of educational stress for dropout is especially relevant as dropout intentions may be seen as a coping mechanism in response to stress (i.e., escape-avoidance coping, see Folkman \& Lazarus, 1988). While the role of stress has already been investigated in relation with dropout intentions and actual dropout, the findings seem rather inconsistent. Chartrand (1992), for example found a significant impact of stress on dropout intentions, Sandler (2000) evidenced an indirect effect through institutional commitment, while others found no or only marginal effects (Metzner \& Bean, 1987; Zajacova, Lynch, \& Espenshade, 2005). However, stress fluctuates over time and therefore stress measured at one point in time may not be a good indicator for analyzing the association between general stress and dropout intentions, thus leading to inconsistent results. We therefore measure educational stress at different points in time and expect that individuals who are more stressed in general think more about dropping out of education.

Positive psychological resources such as optimism may help individuals to deal with environmental demands (e.g., Katz, 1960). Optimism has rarely been included in studies on dropout intentions and dropout. This is surprising, as optimism has been shown to be associated with higher persistence in experimental tasks (Solberg Nes, Segerstrom, \& Sephton, 2005) and higher goal engagement in longitudinal studies (Segerstrom \& Solberg Nes, 2006). The association between optimism and persistence may be explained by the fact that optimism-defined as expecting "positive outcomes, even when things are difficult" (Scheier, Carver, \& Bridges, 2001, p. 191) -is associated with approach-based and problem-focused coping (Scheier, Weintraub, \& Carver, 1986; Solberg Nes \& Segerstrom, 2006) as well as with perceived controllability of stressful events (Chang, 1998a; Scheier \& Carver, 1985): Because optimists expect positive outcomes, they are more persistent in their efforts to achieve their goals than less optimistic individuals. Some studies indeed showed that optimism reduces both dropout intentions (Chemers, Hu, \& Garcia, 2001) and actual dropout (Solberg Nes, Evans, \& Segerstrom, 2009) and has a positive impact on college adjustment in general (Aspinwall \& Taylor, 1992). Following this research, we expect that individuals who are more optimistic in general think less about dropping out than others, because they are better at coping with the demands of their school environment.

Importantly, however, stress and optimism may also interact in predicting dropout intentions. Indeed, prior research has shown that optimism buffers the negative impact of stress on well-being and life satisfaction (e.g., Chang, 1998b). Optimism further appears to be associated with secondary appraisal (evaluation of own coping resources), but not with primary appraisal (evaluation of relevance of the situation) (Chang, 1998a; Lazarus, 1999). As a result, optimists do not necessarily experience less stress, but they believe to possess the necessary resources to cope with it, thus buffering the negative consequences of stress. Therefore, optimism should also buffer the negative impact of educational stress on dropout intentions. 
Prior studies have often examined dropout as an event happening at a precise point in time, that is, they have not taken into account the possibility that dropout intentions may vary or develop over time. Finn (1989) has argued that dropout is a process rather than an event and describes dropping out "as a process of disengagement over time" (p. 133), a view shared by other researchers (Newmann, 1992; Rumberger \& Lim, 2008).

One innovative contribution of the present study is the development and the test of a dynamic regulation model to investigate dropout as a process rather than as an event. To model longitudinal processes of dropout intentions, we include both educational stress and optimism as time-varying regulators of dropout intentions over time. So, in addition to including the general level of stress and optimism, we include the annually varying levels of stress and optimism to investigate their impact on dropout intentions within a given year. This analysis allows a better understanding of the longitudinal process of dropout intentions and its changes over time.

As the level of stress related to education is likely to fluctuate between routine phases and work-intensive and challenging periods (e.g., exams, final school year), we expect that when individuals feel more stressed by their education than usual, they also think more about dropout, compared to less stressful periods. Additionally, although optimism is usually studied as a stable trait over time, it fluctuates over longer periods of time (Carver, Scheier, \& Segerstrom, 2010), particularly during life transitions when outcomes become uncertain. As with general optimism, we expect that when individuals feel more optimistic than usual, they express less dropout intentions than during less optimistic periods.

\section{Context of the research}

The current study investigates dropout intentions of young adults in post-compulsory education in Switzerland over a period of four years. To put the study in context, some background information on the educational system in Switzerland is warranted. Switzerland has a federalist political system in which cantons have large autonomy over their educational systems, leading to considerable variation across Switzerland. Generally, compulsory schooling lasts 11 years (including kindergarten) with most students reaching 15 or 16 years at the end of compulsory schooling.

At this stage, they can choose between a vocational or college-track education. Students in the vocational-track follow a 2-4 years professional training during which they usually enter the labor market as apprentices. Students in the college-track follow a general education program preparing them for higher education, in particular university. Data from 2006 show that about $65 \%$ of adolescents start vocational training, 30\% start college-track education, about 3\% find temporary solutions before starting post-compulsory education (e.g., internship), and only 2\% do not start a new education (Keller \& Moser, 2013). Data from 2013 show that $10 \%$ of 19 year-olds in Switzerland do not have a post-compulsory diploma, 8\% of which started an education but dropped out. Students dropping out of college cite bad grades (73\%) and motivational problems (43-59\%) as reasons for their dropout, while vocational-track students most often report problems with their boss and teachers (54\%) and motivational problems (43-50\%, Keller \& Moser, 2013). Studies show that students with migratory background, students from families with lower SES, students with a disrupted school career (e.g., repeating a school year) and those who attend schools with basic requirements (vs. more advanced requirements) are more likely to drop out of education than others (Gaupp, Geier, Lex, \& Reissig, 2011; Hupka-Brunner, Gaupp, Geier, Lex, \& Stalder, 2011).

\section{Hypotheses}

By focusing on dropout intentions as a dynamic regulation process, stress and optimism are analyzed as time-varying regulators of dropout intentions over time. This approach extends prior research that has investigated dropout as a function of demographic background characteristics, performance indicators, and potentially time-varying characteristics (e.g., stress), but only at one point in time. We thereby go beyond the analysis of stable person characteristics (who drops out?) to time-varying indicators (when do individuals think of dropping out?). More precisely, we analyze dropout intentions over time as a function of both stable and temporary aspects of stress and optimism. Our specific hypotheses are as follows:

1. Over and above stable person characteristics and performance indicators (i.e., gender, country of birth, SES, educational activity, PISA score), average stress (hereafter person-stress) is positively associated with dropout intentions, while average optimism (hereafter person-optimism) is negatively associated with dropout intentions.

2. Controlling for average stress and optimism, annually varying levels of stress and optimism (hereafter annual-stress and annual-optimism) are associated with dropout intentions.

3. The negative effect of stress on dropout intentions is moderated by optimism such that stress has less impact on dropout intentions at high levels of optimism.

In addition to these hypotheses, we test the link between dropout intentions and actual dropout to assess the predictive power of dropout intentions on dropout. 


\section{Method}

\section{Participants}

Our analyses are based on data from a panel study on youth transitions in Switzerland (Transitions from education to employment, TREE). ${ }^{1}$ TREE is the first longitudinal study in Switzerland to survey young adults' post-compulsory educational pathways and their entry into labor market. The TREE sample is based on approximately 6000 young students who participated in the PISA survey (Program for International Student Assessment) in 2000 and is representative on the national level as well as for the Swiss language regions (Stalder, Meyer, \& Hupka-Brunner, 2011). TREE started in 2000 and data was collected in 2001-2007 with an additional follow-up in 2010. Response rates were good, varying between $76 \%$ and $88 \%$ in each wave (Sacchi, 2011).

In this study, we use data from four years (2001-2004) when participants were in transition from lower secondary (end of compulsory schooling) to upper secondary education. The complete sample (i.e., respondents who participated at least once in the study) includes 6343 students. In order to map longitudinal trajectories of dropout intentions and test our hypotheses, we only included students who were in education (i.e., vocational or college-track) for at least three out of the four years. This resulted in a final sample of 4312 participants, $55.9 \%$ of which were women $(N=2412$ women and 1900 men). The sample included $89.3 \%$ students born in Switzerland $(N=3833)$. Mean age in the first survey year $(2001)$ was $16.45(S D=.62)$ with median age being 16 years (range: $13-20$ years).

The comparison between the study sample $(N=4312)$ and the complete sample $(N=6343)$ shows that women $(55.9 \%$ vs. $54.2 \%)$, Swiss (89.3\% vs. $85.7 \%$ ), students in college-track (43.3\% vs. $39.4 \%$ in Wave 1 ), as well as students with higher SES $(M=51.88$ vs. $M=50.38)$ and PISA score $(M=529.25$ vs. $M=510.01)$ are slightly overrepresented in our sample, a result in line with the panel attrition analyses by Sacchi (2011).

For the final analyses we retained the two predominant educational tracks in Switzerland, that is, vocational and collegetrack. College-track also included students who had already started university (i.e., high school, university of applied sciences, and university). Students who did an additional final school year (labeled as 'Compulsory school' in Table 1) or were engaged in other activities (e.g., internship, year abroad, labeled as 'Other') were not included, as these are generally short-term activities. Table 1 shows the number of participants for each educational activity for each year.

Table 1

Number of participants in vocational and college tracks from 2001 to 2004.

\begin{tabular}{|c|c|c|c|c|c|c|c|c|c|c|}
\hline & \multirow[t]{2}{*}{ NA } & \multirow{2}{*}{$\begin{array}{l}\text { Compulsory } \\
\text { school }\end{array}$} & \multirow{2}{*}{$\frac{\text { Vocational track }}{\text { Apprenticeship }}$} & \multicolumn{3}{|c|}{ College-track } & \multirow[t]{2}{*}{ Other } & \multirow[t]{2}{*}{ Employed } & \multirow[t]{2}{*}{ NEET } & \multirow[t]{2}{*}{ Missing } \\
\hline & & & & High school & $\begin{array}{l}\text { University } \\
\text { of Applied Sciences }\end{array}$ & University & & & & \\
\hline 2001 (16 y) & 110 & 273 & 2147 & 1640 & 0 & 0 & 104 & 26 & 10 & 2 \\
\hline $2002(17 \mathrm{y})$ & 112 & 1 & 2561 & 1591 & 8 & 0 & 12 & 15 & 11 & 1 \\
\hline $2003(18 \mathrm{y})$ & 128 & 0 & 2570 & 1549 & 28 & 4 & 13 & 11 & 9 & 0 \\
\hline 2004 (19 y) & 309 & 0 & 1535 & 1097 & 65 & 347 & 266 & 543 & 149 & 1 \\
\hline
\end{tabular}

Note. $\mathrm{NA}=$ respondents did not participate in that year, NEET = respondents are Not in Education, Employment or Training. All rows sum up to 4312 participants. Vocational track (Apprenticeship) and College-track (High school, University of Applied Sciences, and University) were included in the study.

\section{Measures}

Respondents completed a paper-and-pencil questionnaire or telephone interview in which they were asked about their education, employment careers as well as other factors associated with education. Data collections were carried out between March and August, with most of data collections taking place between April and June. ${ }^{2}$ Only the variables used in this study will be presented here. Next to socio-demographic information (i.e., gender, country of birth, SES), we had access to the reading score of the PISA survey of each student (Weighted Likelihood Estimation) that we used as a performance indicator. Additionally, the following variables were asked each year.

Education was asked each year and was coded into 22 categories, collapsed into nine categories: compulsory school, vocational training, high school, university of applied sciences, university, graduate studies, other educational activity (e.g., internship), employment, and 'not in Education, Employment or Training' (NEET).

Educational stress was measured with five items adapted from a scale on work analysis (Prümper, Hartmannsgruber, \& Frese, 1995) with a scale from 1 (very rarely/never) to 5 (very often/always). The measure is typically used as a measure of work conditions (e.g., Wegge, van Dick, Fisher, Wecking, \& Moltzen, 2006) and was adapted to the school context. Example items were: At school I often feel out of my depth and I hardly manage the amount of homework. Cronbach's alpha ranged from .78. to .82 .

\footnotetext{
${ }^{1}$ The Swiss youth panel study TREE runs since 2000 and has since been funded by the Swiss National Science Foundation, the University of Basel, the Swiss Federal Office of Statistics, the Federal Office of Professional Education and Technology, and the cantons of Berne, Geneva and Ticino (www.tree. unibas.ch).

${ }^{2}$ We tested whether the month of data collection influenced dropout intentions and other results presented in this study, but no effects were found.
} 
Table 2

Logistic regression analyses on actual dropout as a function of dropout intention.

\begin{tabular}{|c|c|c|c|c|c|c|}
\hline & \multicolumn{2}{|l|}{ Dropout 2002} & \multicolumn{2}{|l|}{ Dropout 2003} & \multicolumn{2}{|l|}{ Dropout 2004} \\
\hline & B (S.E.) & O.R. & B (S.E.) & O.R. & B (S.E.) & O.R. \\
\hline Dropout intention $\mathrm{t}-1$ & $.527(.034)$ & $1.69^{* * *}$ & $.557(.045)$ & $1.75^{* * *}$ & $.312(.058)$ & $1.37^{* * *}$ \\
\hline Men & $-.125(.167)$ & .88 & $-.254(.201)$ & .78 & $-.253(.210)$ & .78 \\
\hline Non-Swiss & $.011(.256)$ & 1.01 & $.649(.259)$ & $1.91^{*}$ & $.021(.335)$ & 1.02 \\
\hline SES & $-.003(.005)$ & .99 & $-.008(.006)$ & .99 & $.012(.006)$ & 1.01 \\
\hline PISA score & $-.001(.001)$ & .99 & $-.001(.001)$ & .99 & $.003(.001)$ & $1.00^{*}$ \\
\hline
\end{tabular}

Note. S.E. $=$ Standard Error, O.R. $=$ Odds Ratio.

${ }^{*} p<.05,{ }^{* *} p<.01,{ }^{* * *} p<.001$.

Positive outlook on life (optimism) was measured with five items (Grob, 1993; Grob, Little, Wanner, Wearing, \& Euronet, 1996) with a scale from 1 (completely wrong) to 6 (completely right). Example items were: Whatever happens, I can see the positive side of it and My future looks bright. Cronbach's alpha ranged from .82. to .85 .

Dropout intentions were measured with one item specifically developed for the TREE survey that was rated on a scale from 1 (hardly ever) to 7 (almost always): What do you generally think of your education lately: As soon as I find something better I will change my education/apprenticeship.

Actual dropout was measured with one item: Since the last time that we have contacted you in "month/year", did any of the following happen to you: I have quit a school or an apprenticeship. Response options were (1) no, never, (2) yes, once, (3) yes, twice, (4), yes, three times or more. This item was recoded as a dichotomous variable regrouping the options (2)-(4) versus (1) (i.e., yes versus no).

\section{Data analysis}

Multilevel analyses with individuals at level-2 and measurement points at level-1 were conducted with the statistical software R (R Core Team, 2012) and the package lme4 (Bates, Maechler, \& Bolker, 2012). All level-2 variables were grand-mean centered. Following Hoffman and Stawski (2009), we included our main variables of interest (i.e., stress and optimism) twice in the model: At level-2, we included the average level of stress and optimism for a given respondent over four years (labeled Person-stress and Person-optimism). At level-1, we included the four yearly measures for each respondent as person-meancentered variables (labeled Annual-stress and Annual-optimism). These variables indicate the deviation from the personmean controlling for average levels of a respondent. The following example illustrates the meaning of the two variables: Participants A and B both indicate a stress value of 3 in year 2003. Participant A has on average a stress level of 3 (Personstress), while participant B has an average stress level of 2 (Person-stress). Annual-stress in 2003 for participant A is 0 (3-3), while it is 1 (3-2) for participant B. Although both participants indicate the same amount of stress in 2003, there is an increase in stress for participant $B$, and no change for participant $A$. By differentiating the average effect from the annual effect, we are able to investigate whether it is the average stress level of a person that makes her think about dropping out (individual-level effect) or if it is the specific stress in that year (within-person effect).

\section{Results}

\section{Dropout intentions and actual dropout}

Before testing the formal hypotheses, we examined the link between dropout intentions and actual dropout one year later to assess the predictive power of dropout intentions. We did these analyses with the complete sample, as most of the dropouts would be missing from our study sample (that included only students who were in education for at least 3 of the 4 years). The descriptive statistics of self-declared dropout indicated that many participants quit in their final year of education. A chi-square test confirmed that for each year, participants in their final year were more likely to quit education than other participants (all $X^{2} s(9)>163.25$, all $p s<.001$ ), suggesting that the item was ambiguous: Participants may have reported that they quit because they finished their education regularly (the item formulation did not specify reasons for quitting school). We therefore recoded participants who quit in their final year to be non-dropouts. ${ }^{3}$ We performed three logistic regression analyses (years 2001-2002, 2002-2003, 2003-2004) to test whether dropout intentions significantly predicted dropout (yes vs. no) in the following year, controlling for person characteristics (i.e., gender, country of birth, SES, and PISA score). Results in Table 2 show that dropout intentions significantly predicted dropout one year later.

Additionally, we compared the means of dropout intentions between participants who dropped out in the following year versus those who did not. Due to unequal sample sizes and variances, we performed Welch's $t$-tests, which showed that individuals who quit reported higher dropout intentions one year before than those who did not quit: Participants who quit

\footnotetext{
${ }^{3}$ We also performed the logistic regression analyses including the participants in the final year as dropouts, but this did not alter the results.
} 
Table 3

Correlations, means and standard deviations for main variables for waves 1-4.

\begin{tabular}{|c|c|c|c|c|}
\hline & & Dropout intentions (scale $1-7$ ) & Stress (scale 1-5) & Optimism (scale 1-6) \\
\hline$M(S D)$ & $\mathrm{t} 1$ & $1.71(1.46)$ & $2.44(.77)$ & $4.75(.79)$ \\
\hline$M(S D)$ & t2 & $1.54(1.18)$ & $2.41(.74)$ & $4.79(.79)$ \\
\hline$M(S D)$ & t3 & $1.48(1.14)$ & $2.38(.76)$ & $4.77(.79)$ \\
\hline$M(S D)$ & $\mathrm{t} 4$ & $1.83(1.49)$ & $2.39(.81)$ & $4.75(.80)$ \\
\hline$r$ & $\mathrm{t} 1-\mathrm{t} 2$ & $.27^{* * *}$ & $.52^{* * * *}$ & $.60^{* * *}$ \\
\hline$r$ & $\mathrm{t} 2-\mathrm{t} 3$ & $.28^{* * *}$ & $.62^{* * *}$ & $.65^{* * *}$ \\
\hline$r$ & $\mathrm{t} 3-\mathrm{t} 4$ & $.26^{* * *}$ & $.56^{* * * *}$ & $.66^{* * *}$ \\
\hline$r$ & $\mathrm{t} 1-\mathrm{t} 3$ & $.19^{* * *}$ & $.45^{* * *}$ & $.54^{* * *}$ \\
\hline$r$ & $\mathrm{t} 2-\mathrm{t} 4$ & $.14^{* * *}$ & $.47^{* * *}$ & $.58^{* * *}$ \\
\hline$r$ & $\mathrm{t} 1-\mathrm{t} 4$ & $.14^{* * * *}$ & $.32^{* * * *}$ & $.50^{* * *}$ \\
\hline
\end{tabular}

Note. ${ }^{* * *} p<.001$.

education in Wave 2 reported higher dropout intentions in Wave $1(M=3.90, S D=2.47, N=198)$ than participants who did not quit $(M=1.65, S D=1.37, N=3854)$ and the difference was significant $t(203.3)=-12.72, p<.001$. Likewise, participants who quit education in Wave 3 reported higher dropout intentions in Wave $2(M=3.27, S D=2.24, N=136)$ than participants who did not quit $(M=1.50, S D=1.13, N=3790 ; t(137.5)=-9.16, p<.001)$ and the same was true for participants who quit in Wave $4(M=2.13, S D=1.85, N=113)$ versus those who did not quit $(M=1.51, S D=1.20, N=3176 ; t(115.4)=-3.54, p=.001)$.

We also compared the means of dropout intentions in Wave 1 between students who participated in Wave 2, versus those who did not participate in Wave 2 to see whether survey dropouts are likely to also be school dropouts. Indeed, students who did not participate in Wave 2 had significantly higher dropout intentions in Wave 1 than those who continued to participate $(M=2.18, S D=1.73, N=482$ vs. $M=1.77, S D=1.53, N=4384 ; t(565.8)=5.00, p<.001)$, but this difference was much smaller than between school dropouts and participants who persisted in education. Overall, these findings suggest that the measure of dropout intention predicts, and therefore anticipates, actual dropout.

\section{Multilevel models on dropout intentions}

We first show descriptive statistics of the main variables in our model along with correlations between the different waves (Table 3). Participants occasionally thought about dropping out, but the rather low correlations between waves indicate high variability within individuals over the years. Perceived educational stress was low to moderate and perceived optimism was

Table 4

Unstandardized coefficients and standard errors in multilevel models on dropout intentions.

\begin{tabular}{|c|c|c|c|c|}
\hline & Intercept-only model & Model 1 & Model 2 & Model 3 \\
\hline & B (S.E.) & B (S.E.) & B (S.E.) & B (S.E.) \\
\hline Intercept & $1.577(.013)^{* * *}$ & $1.492(.023)^{* * *}$ & $1.508(.024)^{* * *}$ & $1.504(.023)^{* * *}$ \\
\hline Time (linear) (L-1) & & $-.046(.011)^{* * *}$ & $-.054(.011)^{* * *}$ & $-.049(.010)^{* * *}$ \\
\hline Time (quadratic) (L-1) & & $.057(.010)^{* * *}$ & $.050(.010)^{* * *}$ & $.046(.009)^{* * *}$ \\
\hline Men (L-2) & & $.130(.027)^{* * *}$ & $.127(.027)^{* * *}$ & $.127(.027)^{* * *}$ \\
\hline Non-Swiss (L-2) & & $.037(.044)$ & $.037(.044)$ & $.042(.044)$ \\
\hline SES (L-2) & & $.000(.001)$ & $.000(.001)$ & $.000(.001)$ \\
\hline PISA score (L-2) & & $-.002(.000)^{* * *}$ & $-.002(.000)^{* * *}$ & $-.002(.000)^{* * *}$ \\
\hline Education: College-track (L-1) & & $-.099(.029)^{* * *}$ & $-.123(.030)^{* * *}$ & $-.126(.030)^{* * *}$ \\
\hline Person-stress (L-2) & & $.105(.022)^{* * *}$ & $.113(.022)^{* * *}$ & $.111(.022)^{* * *}$ \\
\hline Annual-stress (L-1) & & & $.162(.023)^{* * *}$ & $.132(.027)^{* * *}$ \\
\hline Person-optimism (L-2) & & $-.326(.020)^{* * *}$ & $-.319(.020)^{* * *}$ & $-.308(.020)^{* * *}$ \\
\hline Annual-optimism (L-1) & & & $-.269(.024)^{* * *}$ & $-.214(.028)^{* * * *}$ \\
\hline Person-stress*Person-optimism & & & & $-.033(.027)$ \\
\hline Person-stress*Annual-optimism & & & & $-.042(.043)$ \\
\hline Annual-stress*Person-optimism & & & & $-.111(.038)^{* *}$ \\
\hline Annual-stress*Annual-optimism & & & & $-.213(.058)^{* * *}$ \\
\hline Level-2 variance & .361 & .331 & .357 & .336 \\
\hline Level-1 variance & 1.221 & .912 & .844 & .732 \\
\hline Time (linear) variance & & .135 & .130 & .081 \\
\hline Time (quadratic) variance & & .055 & .055 & .009 \\
\hline Annual-stress variance & & & & .403 \\
\hline Annual-optimism variance & & & & .537 \\
\hline Deviance & 42,589 & 38,283 & 35,540 & 35,019 \\
\hline $\mathrm{AIC} / \mathrm{BIC}$ & $42,595 / 42,617$ & $38,317 / 38,443$ & $35,578 / 35,717$ & $35,083 / 35,318$ \\
\hline
\end{tabular}

Note. L-1 denotes variables included at level 1 (within-person) and L-2 denotes variables included at level 2 (between-person).

${ }^{*} p<.05,{ }^{* *} p<01,{ }^{* * *} p<.001$. 


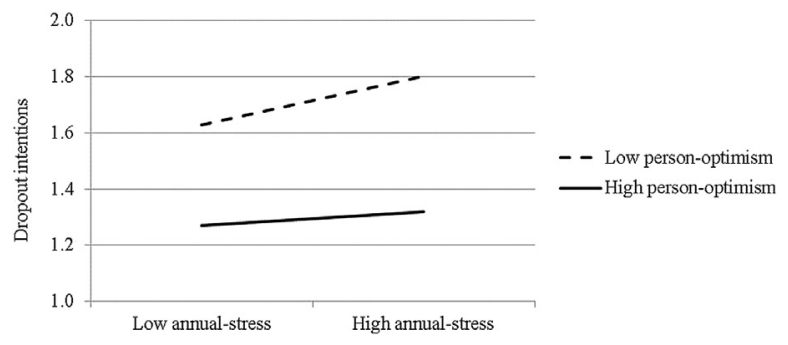

Fig. 1. Interaction between annual-stress and person-optimism on dropout intentions.

relatively high. The two independent variables were more stable than dropout intentions over the years, with optimism having the highest correlations over the four waves. Bivariate correlations between stress and optimism ranged from $r=-.27$ to -.24 for the different waves.

We then tested our hypotheses by running four multilevel models in which we subsequently added the variables. The intercept-only model, without any predictors (see Table 4) partitions the variance in between- and within-person variation. The model yields an intraclass correlation coefficient of .23, suggesting that $23 \%$ of variance in dropout intentions was between persons, while $77 \%$ was within persons.

In a second step, we included time as fixed and random effects as well as all level-2 variables (Model 1 in Table 4): Both the linear and quadratic functions of time were significant, indicating that dropout intentions first declined and then increased again. We included random effects of time because they significantly improved the model, but as we are not interested in modeling between-person differences over time, we will not comment them further. Most of level-2 variables had a significant impact on dropout intentions. Men, students in vocational-track, and academically weak participants expressed higher dropout intentions than others. The absence of effects for country of birth and SES was due to the PISA score (measure of educational performance) that captured most of the variance of country of birth and SES: Without the PISA score in the model, participants who were born outside Switzerland and those with low SES backgrounds expressed higher dropout intentions than others. In line with hypothesis 1 , greater perceived stress over four years (Person-stress) was associated with higher dropout intentions, whereas greater optimism over four years (Person-optimism) decreased dropout intentions. Model fit significantly improved as indicated by model fit indices and a significant chi square difference test, $X^{2}(14)=4305$, $p<.001$.

For Model 2, we added the annual components of stress and optimism. Both annual-stress and annual-optimism significantly affected dropout intentions over and above person-stress and person-optimism, thereby confirming our second hypothesis. As expected, annual-stress was an even stronger predictor for dropout intentions than person-stress, while the opposite was true for optimism. Model 2 was significantly better than Model 1 as shown by model fit indices and a significant chi square difference test, $X^{2}(2)=2743, p<.001$.

In order to test if the two time-varying variables significantly varied between persons, we included them as random effects (one by one) and tested these models against the previous one. All random effects were significant (all $X^{2} \mathrm{~s}(4)>249$, all ps $<.001)$, indicating that the impact of annual-stress and annual-optimism on dropout intentions was different across persons.

In a final step, we tested a third model in which we added the interaction terms between stress and optimism at the person and annual level. Model 3 shows all four interaction effects in a single model. ${ }^{4}$ Annual-stress was buffered by person- and annual-optimism, while person-stress was not moderated. Figs. 1 and 2 show the two significant interaction effects. Optimistic individuals with more annual stress than usual did not think more about dropping out, while unoptimistic individuals with more stress than usual thought more about dropping out. Likewise, individuals with more annual stress than usual thought more about dropping out, in particular when they were also less optimistic than usual. This final model was significantly better than the model with only random slopes as indicated by model fit indices and a significant chi square difference test, $X^{2}(4)=24, p<.001$.

\section{Discussion and conclusion}

School dropout leads to negative consequences for the individual and society. Understanding the steps leading to dropout is therefore crucial in developing effective prevention programs. Results of this longitudinal study show that dropout intentions reliably predict actual dropout one year later. Additionally, they reveal that educational stress led to higher dropout intentions, both on the person level (stressed persons thought more about dropping out than non-stressed persons) and on the annual level (more stress than usual led to higher dropout intentions). Likewise, optimism towards life decreased dropout intentions on both person and annual levels. Finally, the impact of perceived annual stress was buffered by optimism such

\footnotetext{
${ }^{4}$ Interaction coefficients were not noticeably different when included one by one or in a single model. For ease of presentation, Table 4 presents the coefficients of the single model containing all four interaction terms.
} 


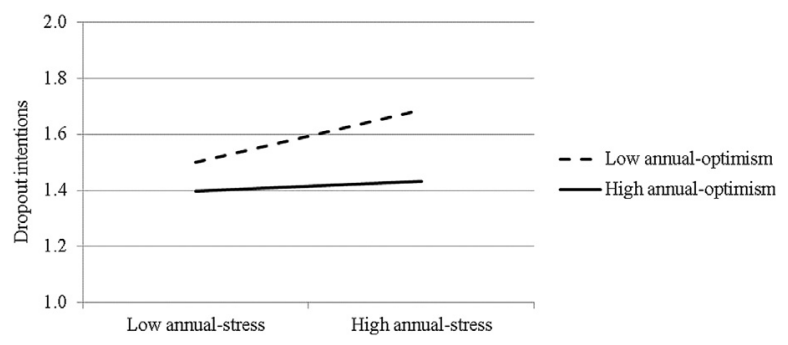

Fig. 2. Interaction between annual-stress and annual-optimism on dropout intentions.

that stress affected in particular those respondents with low levels of optimism. These results yield several important conclusions.

First, our findings show the importance of studying dropout intentions, in addition to actual dropout. Consistent with previous findings, students who indicated dropout intentions were more likely to have dropped out of school one year later and many predictors of dropout were also reliable predictors of dropout intentions, including educational performance. Most importantly, and moving beyond previous research, we found that dropout intentions vary over time (within persons) more than between individuals. As students get older, dropout intentions first decrease before increasing again. This emphasizes the importance of studying dropout intentions as a dynamic process that varies within individuals across periods in time.

Second, optimism as a positive attitude towards life decreases dropout intentions, whereas stress as a feeling of being overwhelmed by one's education increases dropout intentions, even when controlling for stable person characteristics and academic achievement. Although prior research has investigated the effects of different psychological variables (e.g., academic and social integration), stress and optimism have rarely been considered. Here, both have a clear impact, and optimism has even been shown to buffer the negative effect of stress, thereby further decreasing dropout intentions. This moderating effect of optimism is especially important as it may help in developing intervention programs to help students cope with stressful periods. Besides analyzing what makes students want to quit, future research should also investigate the kind of resources that may be used to overcome or counteract dropout intentions.

Finally, our results point to the importance of longitudinal studies in analyzing dropout intentions and dropout. Controlling for average levels of stress and optimism (person-variables), more stress and less optimism than usual led to higher dropout intentions. This is important as we know that dropout intentions are not stable and may thus be influenced by periods of stress, but also by periods in which well-being is especially high. It is important to note here that annual-stress (and -optimism) was measured as more or less stress (and optimism) than usual for a specific person. The annual effects thus show that deviations from one's individual standard make dropout intentions more or less likely rather than absolute levels of stress in a given period. If we know at which moments in time students develop higher dropout intentions than usual, it may be possible to intervene specifically during difficult periods which occur in most students' lives instead of targeting specific groups of students (e.g., minority members).

Some limitations of the study need to be acknowledged. First, our analyses are based on a representative sample of young Swiss adults in post-compulsory education. Although attrition rates were low, young adults who dropped out of the survey (many of them presumably because they dropped out of school) had also higher dropout intentions. Our analyses are thus based on a positively biased sample of young adults, which also explains the relatively low frequency of dropout intentions. It is, however, important to note that even in this sample, within-person variation was high, indicating that dropout intentions are not limited to marginal groups.

Second and related to the previous point, this study focused on a longitudinal investigation of dropout intentions rather than actual dropout. As dropout intentions can only be measured for students who are in education, our sample excluded many actual dropouts. It would be interesting to combine the analysis of dropout intentions with actual dropout and focus on the relationship between intentions and actual dropout to determine in which situations individuals decide to stay in education in spite of dropout intentions. This would give new impulses for designing intervention programs and might shift the intervention focus from specific groups of individuals to specific periods within individuals.

Finally, the item on dropout intentions measures intentions to drop out of the current education, and not necessarily the intention to leave education permanently. This is a common problem in dropout research as it is difficult to verify whether students completely dropped out of education, changed schools or started a new education after a break. It is, however, important to note that our theoretical reasoning regarding stress and optimism is directed toward intentions to quit the current education without excluding the possibility that, if students do actually quit, they may start a different education, in which the same reasoning about stress and optimism would then apply.

\section{Acknowledgments}

This publication benefited from the support of the Swiss National Centre of Competence in Research LIVES “Overcoming vulnerability: life course perspectives”, which is financed by the Swiss National Science Foundation. The authors are grateful to the Swiss National Science Foundation for its financial assistance. 


\section{References}

Alexander, K. L., Entwisle, D. R., \& Horsey, C. S. (1997). From first grade forward: early foundations of high school dropout. Sociology of Education, 70 , 87-107. Alexander, K. L., Entwisle, D. R., \& Kabbani, N. (2001). The dropout process in life course perspective: early risk factors at home and school. The Teachers College Record, 103, 760-822.

Appleton, J. J., Christenson, S. L., \& Furlong, M. J. (2008). Student engagement with school: critical conceptual and methodological issues of the construct. Psychology in the Schools, 45, 369-386.

Archambault, I., Janosz, M., Fallu, J.-S., \& Pagani, L. S. (2009). Student engagement and its relationship with early high school dropout. Journal of Adolescence, $32,651-670$.

Aspinwall, L. G., \& Taylor, S. E. (1992). Modeling cognitive adaptation: a longitudinal investigation of the impact of individual differences and coping on college adjustment and performance. Journal of Personality and Social Psychology, 63, 989-1003.

Balfanz, R., Herzog, L., \& Mac Iver, D. J. (2007). Preventing student disengagement and keeping students on the graduation path in urban middle-grades schools: early identification and effective interventions. Educational Psychologist, 42, 223-235.

Bask, M., \& Salmela-Aro, K. (2013). Burned out to drop out: exploring the relationship between school burnout and school dropout. European Journal of Psychology of Education, 28, 511-528.

Bates, D., Maechler, M., \& Bolker, B. (2012). Ime4: Linear mixed-effects models using S4 classes. R package version 0.999999-0 http://CRAN.R-project.org/ package $=$ lme 4 .

Battin-Pearson, S., Newcomb, M. D., Abbott, R. D., Hill, K. G., Catalano, R. F., \& Hawkins, J. D. (2000). Predictors of early high school dropout: a test of five theories. Journal of Educational Psychology, 92, 568-582.

Bean, J. P., \& Metzner, B. S. (1985). A conceptual model of nontraditional undergraduate student attrition. Review of Educational Research, 55, 485-540.

Belfield, C., \& Levin, H. M. (2007). The price we pay: Economic and social consequences of inadequate education. Washington, D.C.: Brookings Institution Press.

Bishop, J. H., \& Mane, F. (2004). The impacts of career-technical education on high school labor market success. Economics of Education Review, 23, $381-402$.

Braxton, J. M., Vesper, N., \& Hossler, D. (1995). Expectations for college and student persistence. Research in Higher Education, 36, $595-611$.

Carver, C. S., Scheier, M. F., \& Segerstrom, S. C. (2010). Optimism. Clinical Psychology Review, 30, 879-889.

Chang, E. C. (1998a). Dispositional optimism and primary and secondary appraisal of a stressor: controlling for confounding influences and relations to coping and psychological and physical adjustment. Journal of Personality and Social Psychology, 74, 1109-1120.

Chang, E. C. (1998b). Does dispositional optimism moderate the relation between perceived stress and psychological well-being?: a preliminary investigation. Personality and Individual Differences, 25, 233-240.

Chartrand, J. M. (1992). An empirical test of a model of nontraditional student adjustment. Journal of Counseling Psychology, 39, $193-202$.

Chemers, M. M., Hu, L.-T., \& Garcia, B. F. (2001). Academic self-efficacy and first year college student performance and adjustment. Journal of Educational Psychology, 93, 55-64.

Davis, L. E., Ajzen, I., Saunders, J., \& Williams, T. (2002). The decision of African American students to complete high school: an application of the theory of planned behavior. Journal of Educational Psychology, 94, 810-819.

Dotterer, A. M., \& Lowe, K. (2011). Classroom context, school engagement, and academic achievement in early adolescence. Journal of Youth and Adolescence, $40,1649-1660$.

Driscoll, A. K. (1999). Risk of high school dropout among immigrant and native Hispanic youth. International Migration Review, 33, $857-875$.

Dunham, R., \& Wilson, G. (2007). Race, within-family social capital, and school dropout: an analysis of Whites, Blacks, Hispanics, and Asians. Sociological Spectrum, 27, 207-221.

Ellenbogen, S., \& Chamberland, C. (1997). The peer relations of dropouts: a comparative study of at-risk and not at-risk youths. Journal of Adolescence, 20, 355-367.

Entwisle, D. R., Alexander, K. L., \& Steffel Olson, L. (2004). Temporary as compared to permanent high school dropout. Social Forces, 82, 1181-1205.

Fall, A.-M., \& Roberts, G. (2012). High school dropouts: Interactions between social context, self-perceptions, school engagement, and student dropout. Journal of Adolescence, 35, 787-798.

Finn, J. D. (1989). Withdrawing from school. Review of Educational Research, 59, 117-142.

Finn, J. D., Gerber, S. B., \& Boyd-Zaharias, J. (2005). Small classes in the early grades, academic achievement, and graduating from high school. Journal of Educational Psychology, 97, 214-223.

Folkman, S., \& Lazarus, R. S (1988). Manual for the ways of coping questionnaire. Palo Alto, CA: Consulting Psychologists Press.

Gaupp, N., Geier, B., Lex, T., \& Reissig, B. (2011). Wege in Ausbildungslosigkeit - Determinanten misslingender Übergänge in Ausbildung von Jugendlichen mit Hauptschulbildung [Paths to a lack of training - determinants of failed transfer into vocational training among adolescents with a junior high school education]. Zeitschrift für Pädagogik, 57, 173-186.

Grob, A. (1993). BWF: Berner Fragebogen zum Wohlbefinden Jugendlicher [Bernese questionnaire to assess adolescents' well-being]. In G. Westhoff (Ed.), Handbuch psychosozialer Messinstrumente [Handbook of psycho-social measurement instruments] (pp. 132-134). Göttingen: Hogrefe.

Grob, A., Little, T. D., Wanner, B., Wearing, A. J., \& Euronet. (1996). Adolescents' well-being and perceived control across 14 sociocultural contexts. Journal of Personality and Social Psychology, 71, 785-795.

Hausmann, L. R., Schofield, J. W., \& Woods, R. L. (2007). Sense of belonging as a predictor of intentions to persist among African American and White firstyear college students. Research in Higher Education, 48, 803-839.

Hoffman, L., \& Stawski, R. S. (2009). Persons as contexts: evaluating between-person and within-person effects in longitudinal analysis. Research in Human Development, 6, 97-120.

Hupka-Brunner, S., Gaupp, N., Geier, B., Lex, T., \& Stalder, B. E. (2011). Chancen bildungsbenachteiligter Jugendlicher: Bildungsverläufe in der Schweiz und in Deutschland [Possibilities of educationally disadvantaged adolescents: educational trajectories in Switzerland and Germany]. Zeitschrift für Soziologie der Erziehung und Sozialisation, 31, 62-78.

Ishitani, T. T. (2006). Studying attrition and degree completion behavior among first-generation college students in the United States. Journal of Higher Education, 77, 861-885.

Katz, D. (1960). The functional approach to the study of attitudes. Public Opinion Ouarterly, 24, 163-204.

Keller, F., \& Moser, U. (2013). Schullaufbahnen und Bildungserfolg: Auswirkungen von Schullaufbahn und Schulsystem auf den Übertritt ins Berufsleben [School trajectories and educational success: Influence of school trajectory and school system on the transition to the labor market]. Zurich: Rüegger Verlag.

Laird, J., Kienzi, G., DeBell, M., \& Chapman, C. (2007). Dropout rates in the United States: 2005. Washington, D.C.: U.S. Department of Education, National Center for Education Statistics.

Lazarus, R. S. (1999). Stress and emotion - A new synthesis. London: Springer.

Loeb, S., \& Page, M. E. (2000). Examining the link between teacher wages and student outcomes: the importance of alternative labor market opportunities and non-pecuniary variation. The Review of Economics and Statistics, 82, 393-408.

Metzner, B. S., \& Bean, J. P. (1987). The estimation of a conceptual model of nontraditional undergraduate student attrition. Research in Higher Education, 27, $15-38$.

Newmann, F. M. (1992). Student engagement and achievement in American secondary schools. New York: Teachers College Press.

Otis, N., Grouzet, F. M., \& Pelletier, L. G. (2005). Latent motivational change in an academic setting: a 3-year longitudinal study. Journal of Educational Psychology, 97, 170-183.

Perreira, K. M., Harris, K. M., \& Lee, D. (2006). Making it in America: high school completion by immigrant and native youth. Demography, 43, 511-536.

Pittman, R. B. (1991). Social factors, enrollment in vocational/technical courses, and high school dropout rates. The Journal of Educational Research, 84, $288-295$. 
Prümper, J., Hartmannsgruber, K., \& Frese, M. (1995). Kurz-Fragebogen zur Arbeitsanalyse [Short questionnaire on work analysis]. Zeitschrift für Arbeits- und Organisationspsychologie, 39, 125-132.

R Core Team. (2012). R: A language and environment for statistical computing. Vienna, Austria: R Foundation for Statistical Computing, ISBN 3-900051-07-0. http://www.R-project.org/.

Rumberger, R. W. (1987). High school dropouts: a review of issues and evidence. Review of Educational Research, 57, 101-121.

Rumberger, R. W. (1995). Dropping out of middle school: a multilevel analysis of students and schools. American Educational Research Journal, $32,583-625$.

Rumberger, R., \& Lim, S. A. (2008). Why students drop out of school: A review of 25 years of research. Santa Barbara, CA: California Dropout Research Project. Retrieved from http://cdrp.ucsb.edu/dropouts/pubs_reports.htm.

Sacchi, S. (2011). Construction of tree panel weights - Documentation for the panel waves from 2000 to 2010. Basel/Zurich: TREE \& cue sozialforschung.

Sandler, M. E. (2000). Career decision-making self-efficacy, perceived stress, and an integrated model of student persistence: a structural model of finances, attitudes, behavior, and career development. Research in Higher Education, 41, 537-580.

Scheier, M. F., \& Carver, C. S. (1985). Optimism, coping, and health: assessment and implications of generalized outcome expectancies. Health Psychology, 4 , $219-247$.

Scheier, M. F., Carver, C. S., \& Bridges, M. W. (2001). Optimism, pessimism, and psychological well-being. In E. C. Chang (Ed.), Optimism \& pessimism: Implications for theory, research, and practice (pp. 189-216). Washington, D.C., US: American Psychological Association.

Scheier, M. F., Weintraub, J. K., \& Carver, C. S. (1986). Coping with stress: divergent strategies of optimists and pessimists. Journal of Personality and Social Psychology, 51, 1257-1264.

Segerstrom, S. C., \& Solberg Nes, L. (2006). When goals conflict but people prosper: the case of dispositional optimism. Journal of Research in Personality, 40, 675-693.

Solberg Nes, L., Evans, D. R., \& Segerstrom, S. C. (2009). Optimism and college retention: mediation by motivation, performance, and adjustment. Journal of Applied Social Psychology, 39, 1887-1912.

Solberg Nes, L., \& Segerstrom, S. C. (2006). Dispositional optimism and coping: a meta-analytic review. Personality and Social Psychology Review, 10, 235-251.

Solberg Nes, L., Segerstrom, S. C., \& Sephton, S. E. (2005). Engagement and arousal: optimism's effects during a brief stressor. Personality and Social Psychology Bulletin, 31, 111-120.

Spady, W. G. (1970). Dropouts from higher education: an interdisciplinary review and synthesis. Interchange, 1, 64-85.

Stalder, B. E., Meyer, T., \& Hupka-Brunner, S. (2011). TREE project documentation. In M. M. Bergman, S. Hupka-Brunner, A. Keller, T. Meyer, \& B. E. Stalder (Eds.), Youth transitions in Switzerland - Results from the TREE Panel Study (pp. 66-85). Zürich: Seismo.

Thomas, S. L. (2000). Ties that bind: a social network approach to understanding student integration and persistence. Journal of Higher Education, 71, $591-615$.

Tinto, V. (1975). Dropout from higher education: a theoretical synthesis of recent research. Review of Educational Research, 45, 89-125.

Vallerand, R. J., Fortier, M. S., \& Guay, F. (1997). Self-determination and persistence in a real-life setting: toward a motivational model of high school dropout. Journal of Personality and Social Psychology, 72, 1161-1176.

Wegge, J., van Dick, R., Fisher, G. K., Wecking, C., \& Moltzen, K. (2006). Work motivation, organisational identification, and well-being in call centre work. Work \& Stress: An International Journal of Work, Health \& Organisations, 20, 60-83.

Zajacova, A., Lynch, S. M., \& Espenshade, T. J. (2005). Self-efficacy, stress, and academic success in college. Research in Higher Education, 46, 677-706.

Zea, M. C., Reisen, C. A., Beil, C., \& Caplan, R. D. (1997). Predicting intention to remain in college among ethnic minority and nonminority students. The Journal of Social Psychology, 137, 149-160. 